\title{
Bacillus species are superior probiotic feed-additives for poultry
}

\section{Editorial}

\section{Bacillus species are superior probiotic feed-additives for poultry}

In the United States today, antibiotics are commonly used in food animals to promote growth and prevent disease, as well as to treat sick animals. The U.S. Food and Drug Administration (FDA) estimates that 14.6million $\mathrm{kg}$ of antibiotics were sold for use in animals in 2012 (FDA, 2014), more than four times the 3.29million $\mathrm{kg}$ of antibiotics sold for human use in 2011 (FDA, 2012). ${ }^{1-3}$ Antibiotics are used primarily in intensive swine, poultry, and feedlot cattle systems, with limited use in dairy cows, sheep, and companion animals. ${ }^{1}$ Therefore, the increasing antibiotic resistance of pathogens led to bans on antibiotics for growth promotion (AGPs) in the European Union in 2006. ${ }^{3}$ In the United States, AGPs are not banned, but the FDA recently issued guidelines for the industry to voluntarily withdraw medically important antibiotics from growth promotion (FDA, 2013a). ${ }^{1,4}$ To eliminate the use of AGPs in poultry industry in Denmark farmers have been using different approaches like incorporation of live microbial feed supplement which beneficially affects the host animal by improving its intestinal microbial balance and management changes to maintain animal productivity. ${ }^{1,4}$ Benefits from probiotic microorganisms have been recognized for over 100years, and as being useful in poultry for 50years..$^{4-10}$ The strains most frequently used as probiotics include lactic acid bacteria (LAB) like Lactobacillus spp., Bifidobacterium spp. and Saccharomyces boulardii which are isolated from traditional fermented products, fruits, gut, feces and breast milk of human subjects. ${ }^{11-14}$ However, some the major challenges of the industry producing probiotics with Lactobacillus spp. and Bifidobacterium spp. are the following:

i. These microorganisms are microaerophilic or strict anaerobic, therefore their production is complex and could be a challenge the handling and production of this microorganisms; ${ }^{15}$

ii. Their growth is slow requiring expensive and elaborate culture medium as the Lactobacillus MRS medium based on the formulations of deMan, Rogosa and Sharpe (MRS) medium that supports luxuriant growth of Lactobacilli spp. and Bifidobacterium ssp. ${ }^{16,17}$ In addition, both microorganism are slow growers;

iii. Their shelf-life in general is short and the product must be maintained at low temperatures, increasing the cost of production. ${ }^{18}$ To resolve the shelf-life problem several approaches have been used from lyophilization or freeze drying to the most recently techniques involving the microencapsulation of Lactobacillus. ${ }^{19-21}$ Spray drying is one of the oldest encapsulation methods adapted to many industrial areas including probiotics to make powders and capture bioactive components. However, high heat treatment during the spray-drying method cause cellular injuries and dead in Lactobacillus and Bifidobacterium species; ${ }^{22}$

iv. Many of Lactobacillus and Bifidobacterium are damage by the gastric juice when they go through the Gastrointestinal (GI)-track. Both genus are temperature-sensitive microorganisms. ${ }^{22,23}$
Volume 2 Issue 3 - 2016

\author{
Alejandro Penaloza Vazquez \\ Oklahoma State University, USA
}

Correspondence: Alejandro Penaloza Vazquez, Visiting Professor, Oklahoma State University, Stillwater, Oklahoma, USA, Email peva@okstate.edu

Received: June 17, 2016 | Published: June 25, 2016

Bacillus is a genus of Gram positive, rod-shaped member of the phylum Firmicutes. ${ }^{24}$ Bacillus species can be strict aerobes or facultative anaerobes. Under stressful environmental conditions, the bacteria can produce spores which remain in a dormant state for long periods. ${ }^{24}$ The genetics and physiology of the large bacterial genus Bacillus is remarkable. ${ }^{25}$ On the other hand, though, where these Gram-positive bacteria live and grow is far from clear. The soil, once considered their habitat, may simply serve as a reservoir. ${ }^{25}$ Several studies have showed that Bacillus spores can be found in the intestinal tracts of animals where they live and multiply actively, raising the question of whether this could be where they live and grow. ${ }^{25-30}$ For instance, has been reported that soil carries approximately $10^{6}$ spores/g of soil while human feces present an average of up to $10^{4}$ spores/g. The numbers of spores found in human feces, is too high to be accounted for principally by ingestion of food contaminated with spores from soil. ${ }^{25}$ This provides further evidence that Bacillus spore formers may have adapted to survival within the intestinal tract of insects and other animals that ingest them, multiply in the GI-track and sporulate at the colon being excreted in the feces, this has been demonstrated in pigs and other animals utilizing molecular biology tools. These results suggested that Bacillus ssp. is commensal bacteria of the GI-track..$^{26,27,31,32}$ Other major advantages of spores over vegetative (LAB) cells are their thermostability to high temperatures spores can survive at $235^{\circ} \mathrm{F}\left(113^{\circ} \mathrm{C}\right)$ for 8 minutes..$^{28,33,34}$ This thermostability property allow incorporate the spores into the feed the during the milling and pelletizing of the feed and other applications as production of vaccines incorporate as adjuvants. ${ }^{28,35,36}$ Spores also can be spray-dried. In addition, spores are resistant to desiccation and other stress factors like bile and low pHs both present in the gastric juice. ${ }^{26,27,32}$ Bacillus spores have different mode of action in the GItrack per se are able to adsorb toxins, induce the innate immunological response through interaction with the Toll-like receptors of the host cells (TLR2 and TLR4), ${ }^{37}$ stimulating of NF-bk pathway increasing the levels of NK cells, induction of cytokines (IFN-g), ${ }^{38,39}$ improve intestinal integrity and stabilize the microflora, enhance the Daily weight gain (DWG) of the chickens and the Feed Conversion Ratio (FCR) ${ }^{26,40}$ Other important characteristic of Bacillus ssp. is their genetic potential, fully sequenced Bacillus ssp. have 3000 to 6000 genes (Big tool box) NCBI Bacillus genomes, whereas Lactobacillus ssp. have from 1800 genes to 3000 genes..$^{41,42}$ 


\section{Conclusion}

Bacillus species are superior probiotic feed-additives for poultry and pigs due to their big genomes with relevant features; they are spore producers which make the product stable for long time and enhancing the bird's intestinal integrity and growth performance.

\section{Acknowledgements}

None.

\section{Conflict of interest}

The author declares no conflict of interest.

\section{References}

1. Teillant A, Laxminarayan R. Economics of antibiotic use in U.S. swine and poultry production. In: The magazine of food, farm, and resource issues. A publication of the Agricultural \& Applied Economics Association; 2015. 30(1):1-11.

2. Bortolaia V, Espinosa-Gongora C, Guardabassi L. Human health risks associated with antimicrobial-resistant enterococci and Staphylococcus aureus on poultry meat. Clin Microbiol Infect. 2016;22(2):130-140.

3. de Vries LE, Hasman H, Rabadan SJ, et al. Sequence-Based Characterization of Tn5801-Like Genomic Islands in TetracyclineResistant Staphylococcus pseudintermedius and Other Gram-positive Bacteria from Humans and Animals. Front Microbiol. 2016;7:576.

4. Vila B, Esteve-Garcia E, Brufau J. Probiotic micro-organisms:100 years of innovation and efficacy; modes of action. Worlds Poult Sci J. 2010;66(3):369-380.

5. Kabir SML. The Role of Probiotics in the Poultry Industry. International Journal of Molecular Sciences. 2009;10(8):3531-3546.

6. Tejero-Sarinena S, Barlow J, Costabile A, et al. Antipathogenic activity of probiotics against Salmonella Typhimurium and Clostridium difficile in anaerobic batch culture systems: Is it due to synergies in probiotic mixtures or the specificity of single strains? Anaerobe. 2013;24:60-65.

7. Mundt E, Collett SR, Berghaus R, et al. Can Bacteriotherapy Using Commercially Available Probiotics, Prebiotics, and Organic Acids Ameliorate the Symptoms Associated With Runting-Stunting Syndrome in Broiler Chickens? Avian Diseases. 2015;59(2):201-206.

8. Ashraf S, Zaneb H, Yousaf MS, et al. Effect of dietary supplementation of prebiotics and probiotics on intestinal microarchitecture in broilers reared under cyclic heat stress. J Anim Physiol Anim Nutr. 2013;97(Supp 1):68-73.

9. Farnworth ER. The evidence to support health claims for probiotics. $J$ Nutr. 2008;138(6):1250S-1254S.

10. Smith JM. A Review of Avian Probiotics. Journal of Avian Medicine and Surgery. 2014;28(2):87-94.

11. Fontana L, Bermudez-Brito M, Plaza-Diaz J, et al. Sources, isolation, characterisation and evaluation of probiotics. British Journal of Nutrition 2013;109(Suppl 2):S35-S50.

12. Munoz-Quezada S, Chenoll E, Vieites JM, et al. Isolation, identification and characterisation of three novel probiotic strains (Lactobacillus paracasei CNCM I-4034, Bifidobacterium breve CNCM I-4035 and Lactobacillus rhamnosus CNCM I-4036) from the faeces of exclusively breast-fed infants. Br J Nutr. 2013;109(Suppl 2):S51-S62.

13. Angmo K, Kumari A, Savitri, et al. Probiotic characterization of lactic acid bacteria isolated from fermented foods and beverage of Ladakh. LWT Food Science and Technology. 2016;66:428-435.
14. Tamang JP, Watanabe K, Holzapfel WH. Review: Diversity of Microorganisms in Global Fermented Foods and Beverages. Front Microbiol. 2016;7:377.

15. Mazo JZ, Ilha EC, Arisi ACM, et al. Bifidobacteria: Isolation, Identification and Use in Probiotic Foods. Boletim Do Centro De Pesquisa De Processamento De Alimentos. 2009;27(1):119-134.

16. Miranda RO, de Carvalho AF, Nero LA. Development of a selective culture medium for bifidobacteria, Raffinose-Propionate Lithium Mupirocin (RPMUP) and assessment of its usage with Petrifilm (TM) Aerobic Count plates. Food Microbiology. 2014;39:96-102.

17. Quartieri A, Simone M, Gozzoli C, et al. Comparison of culture-dependent and independent approaches to characterize fecal bifidobacteria and lactobacilli. Anaerobe. 2016;38:130-137.

18. Huang S, Cauty C, Dolivet A, et al. Double use of highly concentrated sweet whey to improve the biomass production and viability of spraydried probiotic bacteria. Journal of Functional Foods. 2016;23:453-463.

19. Etchepare MD, Barin JS, Cichoski AJ, et al. Microencapsulation of probiotics using sodium alginate. Ciencia Rural. 2015;45(7):1319-1326.

20. Chen H, Song YJ, Liu NN, et al. Effect of complexation conditions on microcapsulation of lactobacillus acidophilus in xanthan-chitosan polyelectrolyte complex gels. Acta Sci Polon-Technol Aliment. 2015;14(3):207-213.

21. Ghorani B, Tucker N. Fundamentals of electrospinning as a novel delivery vehicle for bioactive compounds in food nanotechnology. Food Hydrocolloids. 2015;51:227-240.

22. da Silva PT, Fries LLM, de Menezes CR, et al. Microencapsulation of probiotics by spray drying: evaluation of survival in simulated gastrointestinal conditions and availability under different storage temperatures. Ciencia Rural. 2015;45(7):1342-1347.

23. Sosa N, Gerbino E, Golowczyc MA, et al. Effect of GalactoOligosaccharides: Maltodextrin Matrices on the Recovery of Lactobacillus plantarum after Spray-Drying. Front Microbiol. 2016;7:584.

24. Bergey's Manual of Systematic Bacteriology. USA: The Firmicutes; 2009.

25. Hong HA, To E, Fakhry S, et al. Defining the natural habitat of Bacillus spore-formers. Res Microbiol. 2009;160(6):375-379.

26. Guo XH, Li DF, Lu WQ, et al. Screening of Bacillus strains as potential probiotics and subsequent confirmation of the in vivo effectiveness of Bacillus subtilis MA139 in pigs. Antonie Van Leeuwenhoek. 2006;90(2):139-146.

27. Barbosa TM, Serra CR, La Ragione RM, et al. Screening for Bacillus isolates in the broiler gastrointestinal tract. Appl Environ Microbiol. 2005;71(2):968-978.

28. Chaiyawan N, Tayeeteptaikul P, Wannissorn B, et al. Characterization and Probiotic Properties of Bacillus Strains Isolated from Broiler. Thai Journal of Veterinary Medicine. 2010;40(2):207-214.

29. Chaucheyras-Durand F, Durand H. Probiotics in animal nutrition and health. Benef Mirbobes. 2010;1(1):3-9.

30. Dawood MAO, Koshio S. Recent advances in the role of probiotics and prebiotics in carp aquaculture: A review. Aquaculture. 2016;454:243-251.

31. Lei K, Li YL, Wang Y, et al. Effect of dietary supplementation of Bacillus subtilis B10 on biochemical and molecular parameters in the serum and liver of high-fat diet-induced obese mice. Journal of Zhejiang UniversityScience B. 2015;16(6):487-495.

32. Ma L, Yang WP, Meng FX, et al. Characterization of an acidic cellulase produced by Bacillus subtilis BY 4 isolated from gastrointestinal tract of Tibetan pig. J Taiwan Inst Chem Eng. 2015;56:67-72. 
33. Cho EA, Kim EJ, Pan JG. Adsorption immobilization of Escherichia coli phytase on probiotic Bacillus polyfermenticus spores. Enzyme Microb Technol. 2011;49(1):66-71.

34. Setlow P. Spores of Bacillus subtilis: their resistance to and killing by radiation, heat and chemicals. J Appl Microbiol. 2006;101(3):514-525.

35. Amuguni $\mathrm{H}$, Tzipori S. Bacillus subtilis: a temperature resistant and needle free delivery system of immunogens. Hum Vaccin Immunother. 2012;8(7):979-986.

36. Kwon SJ, Jung HC, Pan JG. Transgalactosylation in a water-solvent biphasic reaction system with beta-galactosidase displayed on the surfaces of Bacillus subtilis spores. Appl Environ Microbiol. 2007;73(7):22512256.

37. Yan YY, Xia HQ, Yang HL, et al. Effects of dietary live or heat-inactivated autochthonous Bacillus pumilus SE5 on growth performance, immune responses and immune gene expression in grouper Epinephelus coioides Aquac Nutr. 2016;22(3):698-707.

38. Lefevre M, Racedo SM, Ripert G, et al. Probiotic strain Bacillus subtilis CU1 stimulates immune system of elderly during common infectious disease period: a randomized, double-blind placebo-controlled study. Immun Ageing. 2015;12:24.
39. Bonavita R, Isticato R, Maurano F, et al. Mucosal immunity induced by gliadin-presenting spores of Bacillus subtilis in HLA-DQ8-transgenic mice. Immunol Lett. 2015;165(2):84-89.

40. Nguyen ATV, Nguyen DV, Tran MT, et al. Isolation and characterization of Bacillus subtilis CH16 strain from chicken gastrointestinal tracts for use as a feed supplement to promote weight gain in broilers. Lett Appl Microbiol. 2015;60(6):580-588.

41. Liu L, Li PL. Complete genome sequence of Lactobacillus paraplantarum L-ZS9, a probiotic starter producing class II bacteriocins. J Biotechnol. 2016;222:15-16.

42. Sun ZH, Harris HMB, McCann A, et al. Expanding the biotechnology potential of lactobacilli through comparative genomics of 213 strains and associated genera. Nat Commun. 2015;6:8322. 